5. Bad results like "boat-shaped" pupil can be avoided by taking as much time as necessary for the moulding of the lens to occur.

6. Traumatic opacification of the cornea does not occur if cocaine is not used too freely and the cornea is kept moist.

7. It reduces the period of hospitalisation. Patients can be discharged from the hospital at the end of a week and in many cases all the reaction of the operation subsides in a fortnight and the eye is white.

\title{
TRANSPLANTATIO CONCHAE AURICULAE AS A NEW METHOD OF CORRECTING SPASTIC ENTROPION OF THE UPPER LID FOLLOWING TOTAL TARSECTOMY*
}

BY

\author{
N. I. SHIMKIN \\ HAIFA, PALESTINE
}

IN 1928, at a sitting of the Ophthalmic Section of the International Congress of Tropical Medicine and Hygiene in Cairo, Egypt, I read a paper entitled "Three cases of Spastic Entropion post tarsectomia totalis of the upper lid, cured by Homoplastica tarsi " (published also in Klin. Monatsbl. f. Augenheilk., Maerz, 1929, S.360-364). I had the opportunity of observing the cases from six to seven years after the operation. In all cases the lid had kept its normal position so that the proposed method of homoplastica tarsi in spastic entropion post tarsectomia totalis has affected its purpose.

But the method "homoplastica tarsi" in suitable cases of spastic entropion has the disadvantage that there is not always material suitable for plastic operation available. When there is a patient with spastic entropion following total tarsectomy, there may be no patient needing tarsectomy whose tarsus could be used for transplantation, and vice versa.

In order to overcome this inconvenience, I decided to make use of the concha auriculae, as a plastic material. The fact that the auricular cartilage is a good plastic material, is mentioned in all manuals of ophthalmic surgery. Buedlinger and Muller's operation for correcting the defects of the eye lid by means of auricular cartilage, has come into general use.

* Paper read on December 10, 1937, in the Assembly of Delegates at the International Organisation against Trachoma. Fifteenth Congress of Ophthalmology, Cairo, Egypt. 
But I did not succeed in finding in any, even the most comprehensive manual of ophthalmic surgery, any indication of the method of correcting spastic entropion of the upper lid resulting from total tarsectomy by means of substituting a graft of conchae auriculae for the tarsus of the lid.

I have observed only five new cases of spastic entropion after total tarsectomy during the past eight years. Possibly such cases are met with more frequently in trachometous countries where the combined Kuhnt-Heisrath excision is often applied with an unsuccessful result. Several authors fearing entropion of the lid after the usual tarsectomy suggest after the removal of the trachomatous tarsus to replace it immediately with cartilage cut out of the helix of the ear. (Dr. Goldfeder, Ein neuer Weg den Eintritt eventueller Liddeformitaeten nach der einfachen Tarsusausschälung vorzubeugen. Klin. Monatsbl. f. Augenheilk., April, 1931, p. 460.)

I now suggest my operation of the transplantation of the concha auriculae for the correction of the already existing spastic entropion after total tarsectomy and not for preventing it in the frequent and straightforward operation of simple tarsectomy. If the sutures, proposed by me as far back as 1913 at the first Conference of Russian Oculists at Moscow, are inserted correctly, and the bulbar conjunctiva is separated deeply enough, there is never an entropion following the combined Kuhnt-Heisrath tarsus excision. (N. Shimkin, Modification of sutures in the Heisrath operation, Westnic. Ophthal., 1914, No. 6, p. 514-523.)

But though rare, precisely those cases of spastic post operative entropion demand the surgeon's particular attention, as such patients apply to the specialist after all the usual methods of operation for the treatment of entropion have already been tried and failed.

On examining the eyes of the above-mentioned patients, we find usually a linear scar on the skin of the lid, $3-4 \mathrm{~mm}$. from the border along all its length from the outer to the inner canthus. This scar is the evidence of a former operation for correcting entropion according to the methods of Snellen, Hotz-Agnostakis, Panes and others. Secondly, canthotomy and 3rd grafting of mucous membrane into the lid according to van Millingen's method has also been performed. Only a narrow strip of tarsus, $\frac{1}{2}-1 \mathrm{~mm}$. wide, is seen on everting the lid.

The clinical picture presented by all patients was as follows :A severe blepharospasm, a complete entropion of the lid border up to $180^{\circ}$ inwards. On drawing by finger the skin of the upper lid upwards, the entropion disappeared, and a pannus ulcerosus of differing degree was observed on the cornea. 
The anatomical reasons for this severe entropion are the following :-

(1) A nearly complete absence of the tarsus of the lid as a consequence of its removal.

(2) Absence of tangential stretching of the lids by means of the fibres of the tarso-orbital fascia, levator palpebrae which is normally fixed to the upper border of the removed tarsus.

(3) Overaction of the musculi palpebralis et subtarsalis (Riolani) in the radial direction, owing to the loss of the antagonistic action of levator palpebrae and fascia tarso-orbitalis.

The concha auriculae is eminently suitable for this purpose of restoring the lid's integrity. The operation of restoring the lid's integrity by means of grafting concha auriculae in the place of the tarsus, previously removed by a Kuhnt-Heisrath excision, is performed in the following way and using the following instruments.

Instruments required.-Jaeger's spatula, a scalpel, sharp-pointed scissors, three silk sutures with one needle at each end, eight silk sutures with one needle each, needle-holder, forceps and a 2 c.c. syringe.

The operation consists of three steps.

First Step (Fig. 1). Excision of the graft from the concha auriculae, its size being equal to that of the lid tarsus, formerly removed.

The pinna of the ear is bent forward by the fingers on to the face, 1 c.c. of 2 per cent. novocaine + adrenalin is injected into the skin of the concha. Then a linear incision, $2 \mathrm{~cm}$. long, is made in the skin of the middle of the concha. The skin of the middle of the concha is movable and separated off easily inwards and outwards, $\frac{3}{4} \mathrm{~cm}$. each way. As the skin should be separated superficially, care should be taken not to touch the epichondrium of the concha auriculae. Cartilage $2 \mathrm{~cm}$. in length and $1 \frac{1}{2} \mathrm{~cm}$. in breadth having been exposed, the border of the cartilage to be excised is outlined with a knife (Fig. $1 \mathrm{~T}$ ). Then, out of the cartilage, a layer of about $\frac{3}{4} \mathrm{~mm}$. thickness is excised by a scalpel laid flat with a sawlike movement. If the scalpel is held flat, the concha is never cut through. The prepared cartilage layer with its epichondrial tissue remains temporarily in its place, and is again covered with skin until the bed in the lid has been prepared.

Second Step (Fig. 2). Preparation of a Bed for the Cartilage.

1 c.c. of novocaine 2 per cent. + adrenalin is injected subcutaneously into the upper lid; the same, under the conjunctiva of the fornix. Then Jaeger's spatula is introduced under the lid. 


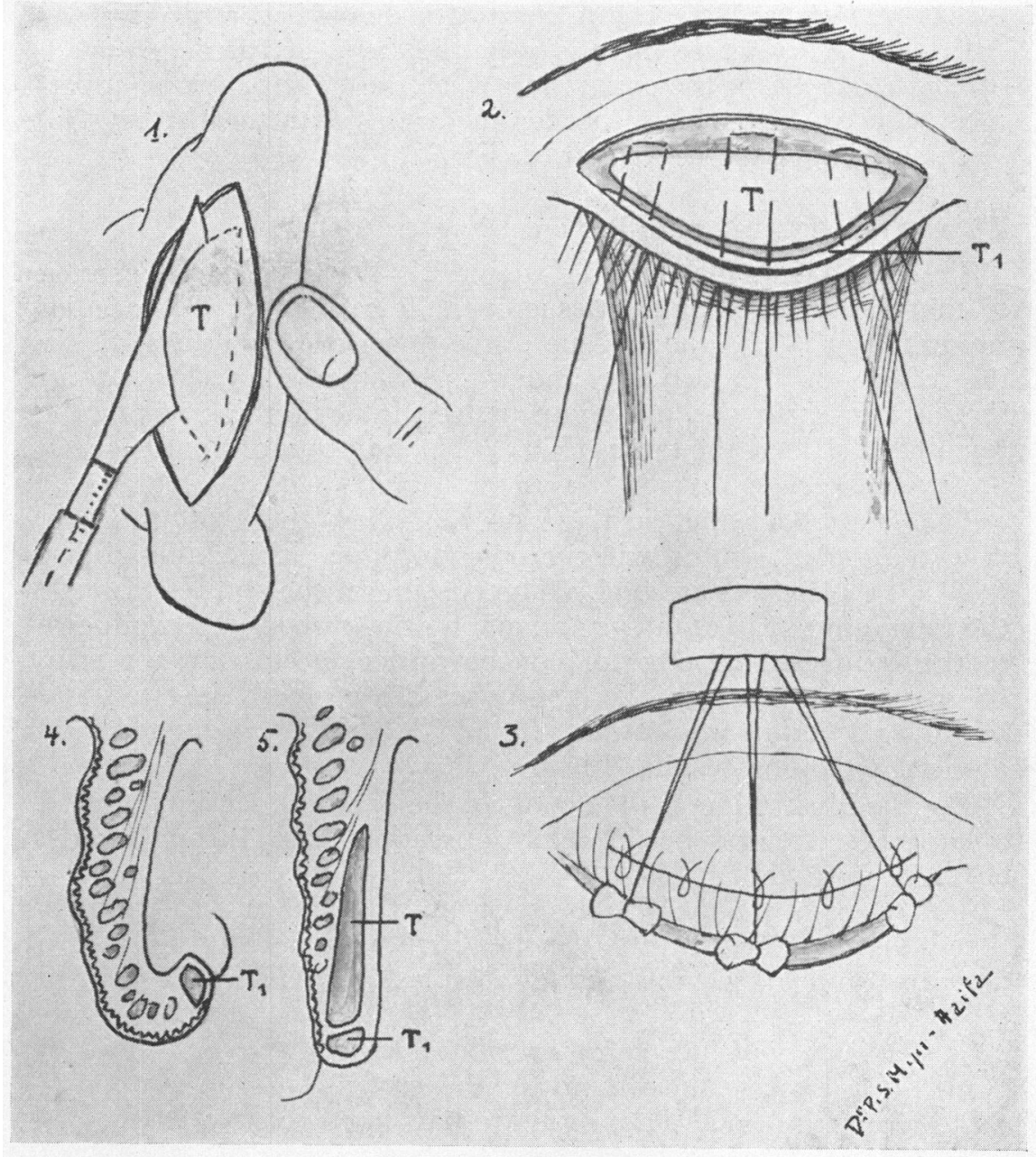

Four or five $\mathrm{mm}$. away from the lid border, an incision is made in the skin from the outer to the inner canthus of the lid; the skin being cautiously separated upwards and downwards. It should be borne in mind that in all cases the skin is always scarred and attached to the underlying tissue as a result of previous operations. The skin should be separated off down to the limit of the lid margin with scrupulous care, so that the base of eyelashes may be seen. The traces of the musculus ciliaris Riolani on the remainder of the tarsus are cut away with scissors, so that a narrow strip of the tarsus which has remained, becomes visible 
(Fig. $2 \mathrm{~T} 1$ ). All the scar tissue in the wound is removed with scissors, and the tissue of the conjunctiva now becomes visible.

In the bed prepared in this way the layer of cartilage, taken from the concha of the ear, is laid with the epichondrium uppermost, and with the lower border in direct contact with the strip of the tarsus which has remained (Fig. $2 \mathrm{~T} 1$ ).

\section{Third Step (Figs. 2 and 3). Inserting Sutures.}

Three Snellen's loop sutures are used. The needles are inserted so that the loop lies on the tissue over the cartilage. The needles brought out of the tissue are inserted superficially in the middle of the cartilage under its epichondrium (Fig. $2 \mathrm{~T}$ ); they are brought out and again pierced into the thickness of the remaining strip of the tarsus (Fig. $2 \mathrm{~T} 1$ ), and brought out between the eyelashes.

The loops over the cartilage do not allow the graft to move upwards and the sutures in the epichondrium further immobilise it, when the sutures are tied. The passing of the sutures through the remaining strip of tarsus and among the eyelashes is conducive to the fitting of the edge of concha auriculae close to the strip of tarsus. As soon as all the sutures are correctly inserted and tied over a cotton wool swab, the lid border is straightened, and a slight ectropion results (Fig 3).

For the illustration of the details of the operation and its results, a sagittal section of the lid before operation (Fig. 4), and after it (Fig. 5) are given.

The edges of the incision are sewn up with five surgical sutures. Then the ends of the three Snellen's sutures are slightly drawn upwards and fixed with adhesive plaster above the eyebrow (Fig 3).

Toilet of the eyelid: xeroform ointment is inserted. Two or three sutures close the wound on the ear. A sterile tampon is laid behind the ear. Both eyes are bandaged for two days. Post-operative period.

Two days after the operation, the bandage is taken off and a sterile pad is worn for two days more. On the fifth day after the operation the sutures are taken out of the lid and ear, a bandage is applied for one day more, and the patient returns home.

After the first bandage, the patient feels better, the pannus diminishes, the ulcers gradually disappear, and the patient usually asserts that he sees better with the other eye too.

The simplicity of the operation and its consistently good results, have emboldened me to draw the attention of eye surgeons to this method of correcting severe cases of spastic entropion following total tarsectomy. 


\title{
Summary
}

The author offers a new method of operation for correcting severe cases of spastic entropion following total tarsectomy. The method consists in a cartilage of corresponding size being taken out of the concha auriculae and laid in the bed prepared in the lid, to replace the tarsus removed by total tarsectomy. The operation consists of three steps described in the text and illustrated in the attached Table.

The author has operated in the above manner on five cases with consistently good results. The patients have been demonstrated before the Haifa Society of Oculists and the Jewish Medical Society in Haifa.

\section{ANTEPOSITIO CONJUNCTIVAE FORNICIS. OPERATION IN SEVERE CASES OF SPRING CATARRH*}

\author{
BY \\ N. I. SHIMKIN \\ HAIFA, PALESTINE
}

IN Palestine, as well as in Egypt, spring catarrh occurs the whole year round, i.e., both during the cold and hot time of the year. But in the hot season, the clinical diagnosis of spring catarrh is not always easy, owing to the presence of trachoma and acute seasonal conjunctivitis in different forms. An immediate clinical determination of the diagnosis becomes especially difficult with the papillary form of trachoma. The exact setting up of a differential diagnosis among the trachoma highly spread in Palestine and the comparatively rare cases of spring catarrh, is possible only after curing acute conjunctivitis, the aetiology and epidemiology of which in Palestine have been expounded by me in a whole series of other articles (Shimkin, Harefua (Hebrew), 1923. Ann. d'Ocul., 1924. Brit. Jl. of Ophthal., 1926. Compte Rendu de Congrès International à Caire, 1931. Tome III).

While according to the data of various authors, up to 65 per cent. of the Arabic population in Palestine is affected with trachoma, and in the South of Palestine, in the villages, even up to 95 per cent., there are no more or less comprehensive statistics of the frequency of spring catarrh in Palestine.

\footnotetext{
* Paper read on December 9,1937. at the Fifteenth Concilium Ophthalmologicum in Cairo, Egypt
} 